\title{
Dynamic NMR and Twisted Intramolecular Charge Transfer Excited States
}

\author{
Iraj Parchamazad*, Debra Hornyak, Melvin Miles \\ Chemistry Department, University of La Verne, La Verne, CA, USA \\ Email: ${ }^{*}$ iparchamazad@laverne.edu
}

Received 5 March 2015; accepted 29 March 2015; published 31 March 2015

Copyright (C) 2015 by authors and Scientific Research Publishing Inc.

This work is licensed under the Creative Commons Attribution International License (CC BY). http://creativecommons.org/licenses/by/4.0/

(c) (i) Open Access

\begin{abstract}
In this paper the results of dynamic NMR studies on ethylmethylamino-tertiary-butyl-phenylborane (EMABPB) with or without light are reported. The NMR data were recorded on a Bruker 400 MHz NMR equipped with our custom-made optical probe and with our custom-made 450 watts (W) monochromatic light sources. The molecular photochemistry including twisted intramolecular charge-transfer-excited-state (TICT) of the EMABPB in several solvents has been investigated. These results indicate that the aminoborane demonstrates multiple configurations in $\mathrm{CD}_{3} \mathrm{Cl}$ and $\mathrm{CD}_{2} \mathrm{Cl}_{2}$ resulting in the shifts of the signals of the alkyl groups on the nitrogen and boron. This indicates that there are some time-dependent changes at constant temperature over the irradiation interval. At $-60^{\circ} \mathrm{C}$ and the presence of light $(\lambda=265 \mathrm{~nm})$, we observed a large change in the populations of the two sites, and this by itself indicates a modification in the rotation around the boron nitrogen bond in the excited state. By considering the existence of the TICT state, many important energy technologies may be developed with higher efficiency by controlling the back-electron transfer processes.
\end{abstract}

\section{Keywords}

Twisted Intramolecular Charge Transfer State, Back Electron Transfer, Twisted Excited State, Dynamic NMR, Rotation around B-N Bond, Molecular Photochemistry inside NMR Probe, Customized Optical Probe, Solvent Effect, Low Temperature Spectra

\section{Introduction}

Dual fluorescence phenomenon of 4-N,N-dimethylaminobenzonitrile (DMABN) and some other compounds in polar solvents have been studied by different scientists over the past several decades [1]-[4]. Various mechan-

*Corresponding author.

How to cite this paper: Parchamazad, I., Hornyak, D. and Miles, M. (2015) Dynamic NMR and Twisted Intramolecular Charge Transfer Excited States. American Journal of Analytical Chemistry, 6, 402-410.

http://dx.doi.org/10.4236/ajac.2015.65039 
isms have been suggested to account for this dual emission: normal fluorescence and an anomalous emission with longer wavelength than normal fluorescence. The more convincing theory was characterized by the existence of the highly polar emitting states in which the two donor and acceptor subsystems were mutually twisted by $90^{\circ}$. These excited states received a name of Twisted-Intramolecular-Charge-Transfer-Excited States (TICT). If this rotation really happens, then after the electron transfer from donor to acceptor, the two excited wave functions will be orthogonal to one another. Therefore, the back electron transfer will be slower. This phenomenon can be used to considerably raise the efficiency of a solar cell, solar hydrogen and other types of solar energy storage and conversion.

This paper discusses the results of investigation in aminoborane model [5] to determine if there is any rotation around the N-B bond in the excited state which results in cis-trans isomerization. The interesting nature of the bonding in aminoboranes makes them a great candidate for an investigation of TICT emission phenomenon, as seen in Figure 1. In the aminoborane structure, there exists primarily only one covalent bond which creates an electron deficiency on boron. The nitrogen atom shares its nonbonding electron with boron intra-molecularly [6]. The planar arrangement of the bonds in the aminoborane enables the nonbonding electron to participate as $\pi$-electrons in the partially double bond. This suggests that the highest occupied molecular orbital (HOMO) is the nitrogen $\pi$ bond, and the $\pi^{*}$ orbital of boron should be the lowest unoccupied molecular orbital (LUMO). The aminoborane model has the advantage that the $\Delta \mathrm{G}^{\circ}$ of rotation around the $\mathrm{B}-\mathrm{N}$ bond of some derivative is high enough that we can study dynamic NMR even at room temperature [7].

\section{Methodology}

The previous publications have presented influential theoretical [8] and experimental proofs for the existence of twisted intramolecular charge transfer (TICT) excited state [9] [10] responsible for the long wavelength emission. However, an exciplex [11] has been suggested for this anomalous emission by other investigators. In this paper, we report a dynamic NMR approach to study the TICT emission. We studied several models such as dialkylamino-pyrimidine and aminoborane derivatives. In our previous investigation we used several dialkylamino pyrimidine derivatives including 4-(ethyl-methylamino) pyrimidine, 4-(isopropyl-methylamino) pyrimidine, and 4-(tert-butyl-methylamino) pyrimidine. In each case we studied their absorption and emission characteristics in different solvents. Their dynamic NMR spectra were recorded in polar solvents such as $\mathrm{CDCl}_{3}, \mathrm{CD}_{2} \mathrm{Cl}_{2}$, $\mathrm{C}_{2} \mathrm{D}_{5} \mathrm{OD}$, and $\mathrm{CH}_{3} \mathrm{CN}$, at temperatures as low as $-100^{\circ} \mathrm{C}$. Because of delocalization of the nonbonding electrons of the amino group through the pyrimidine ring and the formation of a partially double bond between the amino group and the ring, we could observe a cis- and trans-isomers of the pyrimidine molecule in the ground state. For the two sites, the percentage of the different alkyl groups on the amino groups was determined for the two rotamers. Then, we irradiated each sample using uv (with $\lambda=285 \mathrm{~nm}$ and $309 \mathrm{~nm}$ ) outside the NMR instrument at very low temperature, and the corresponding NMR measurements were performed at the same temperatures. We did not observe any difference for the relative populations of the two rotamers before and after irradiation [12]. These studies show that the lifetimes of the two sites may not be long enough to be observed in $400 \mathrm{MHz}$ NMR in order to identify the above mentioned rotation in pyrimidine derivatives.

Several aminoboranes including ethylmethylamino-cholorphenylborane, and ethylmethylamino-tertiary-butylphenylborane were synthesized according to the procedures reported in previous papers [13]-[16] and purified by fractional distillation and preparative HPLC.

The basic synthesis was performed as follows in Scheme 1.

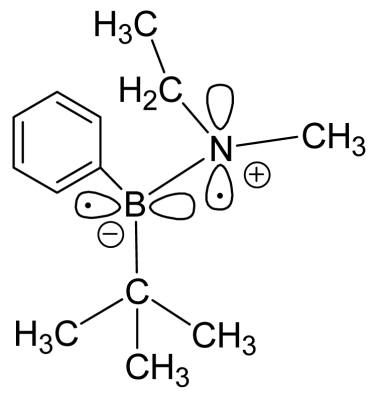

Figure 1. Structure of aminoborane. 
Step 1: Substitution<smiles>CCN(C)P(Cl)c1ccccc1</smiles>

Step 2: Grignard Reaction

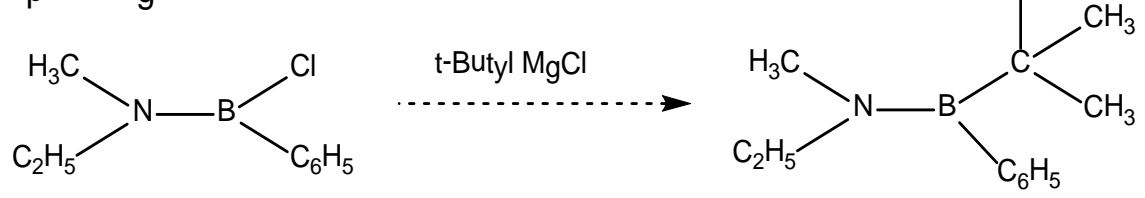

Scheme 1. Synthesis of aminoborane.

To investigate the rotation around the B-N bond dynamic NMR was used in a $400 \mathrm{MHz}$ Bruker NMR equipped with our custom made optical probe [17]. In Figure 2, we utilized our custom-made light source, which is 450 watts and contains a high resolution monochromator. This monochromator can produce the appropriate wavelength in the range of $200-900 \mathrm{~nm}$. The light is relayed from the monochromator to the optical probe via a quartz optical fiber cable. This allowed us to irradiate the sample while it was in the magnetic field.

\section{Results and Discussion}

For the proton NMR study, a few drops of our sample was diluted with the chosen solvent (in this experiment either: $\mathrm{CDCl}_{3}, \mathrm{CD}_{2} \mathrm{Cl}_{2}$, or DMSO) and then a drop of tetramethylsilane (TMS) was added for a reference point. Proton NMR was carefully monitored before and after UV irradiation at 265 - $300 \mathrm{~nm}$. Irradiation intervals ranged from three minutes to one hour. A proton NMR was run the day following irradiation to examine changes to the sample that may have occurred overnight.

In the chloroform samples, proton NMR was run at room temperature, $300 \mathrm{~nm}$ and $270 \mathrm{~nm}$ light intervals, high temperature intervals, low temperature, and low temperature with irradiation. Deuterated methylene chloride samples were run at room temperature, at low temperature intervals, and at low temperature with irradiation intervals. DMSO samples were run at room temperature with and without irradiation and high temperature. No low temperature work could be done with DMSO because of its relatively high freezing point. In studies that were performed at low temperature, liquid nitrogen was utilized. To do this, a liquid nitrogen tank was placed next to the NMR and a hose was connected to the probe. A pressurized system created a flow of the liquid nitrogen through the tubes and into the probe where the sample was located. In this manner, we were able tomonitor the temperature of the sample. As we reached our target temperature we would electronically slow the flow so that we could maintain the temperature. During irradiation, the temperature remained constant. Our low temperature scale ranged from room temperature to $-70^{\circ} \mathrm{C}$.

Figure 3 is an overlay of multiple spectra at constant temperature and it shows our early irradiation results after irradiating the compound at $300 \mathrm{~nm}$ in deuterated chloroform. By monitoring the signal for tertiary butyl group on boron and irradiation at different intervals, we observed changes in the molecule from $1.10-1.15 \mathrm{ppm}$. The original spectrum is in blue. The compound was irradiated for 3 minutes (green), 20 minutes (pink), 30 minutes (yellow), 60 minutes (orange), and 30 minutes after the light was turned off (red). The shifts in the spectra over the irradiation interval indicate that there are some time-dependent changes in the molecule. As can be seen from the previous spectra, this time-dependent movement is occurring in more than one area of the molecule. At this time, it has not yet been determined what this movement is exactly indicating.

Figure 4 shows our early irradiation results after irradiating the compound at $300 \mathrm{~nm}$ in chloroform. This figure is an overlay of multiple spectra. By monitoring the signal for methyl group on Nitrogen and irradiation at different intervals, we observed changes in the molecule from 2.43 - $2.46 \mathrm{ppm}$. The original spectrum is in blue. The compound was irradiated for 3 minutes (green), 20 minutes (pink), 30 minutes (yellow), 60 minutes (orange), and 30 minutes after the light was turned off (red). The shifts in the spectra over the irradiation interval indicate that there are some time-dependent changes in the molecule. 


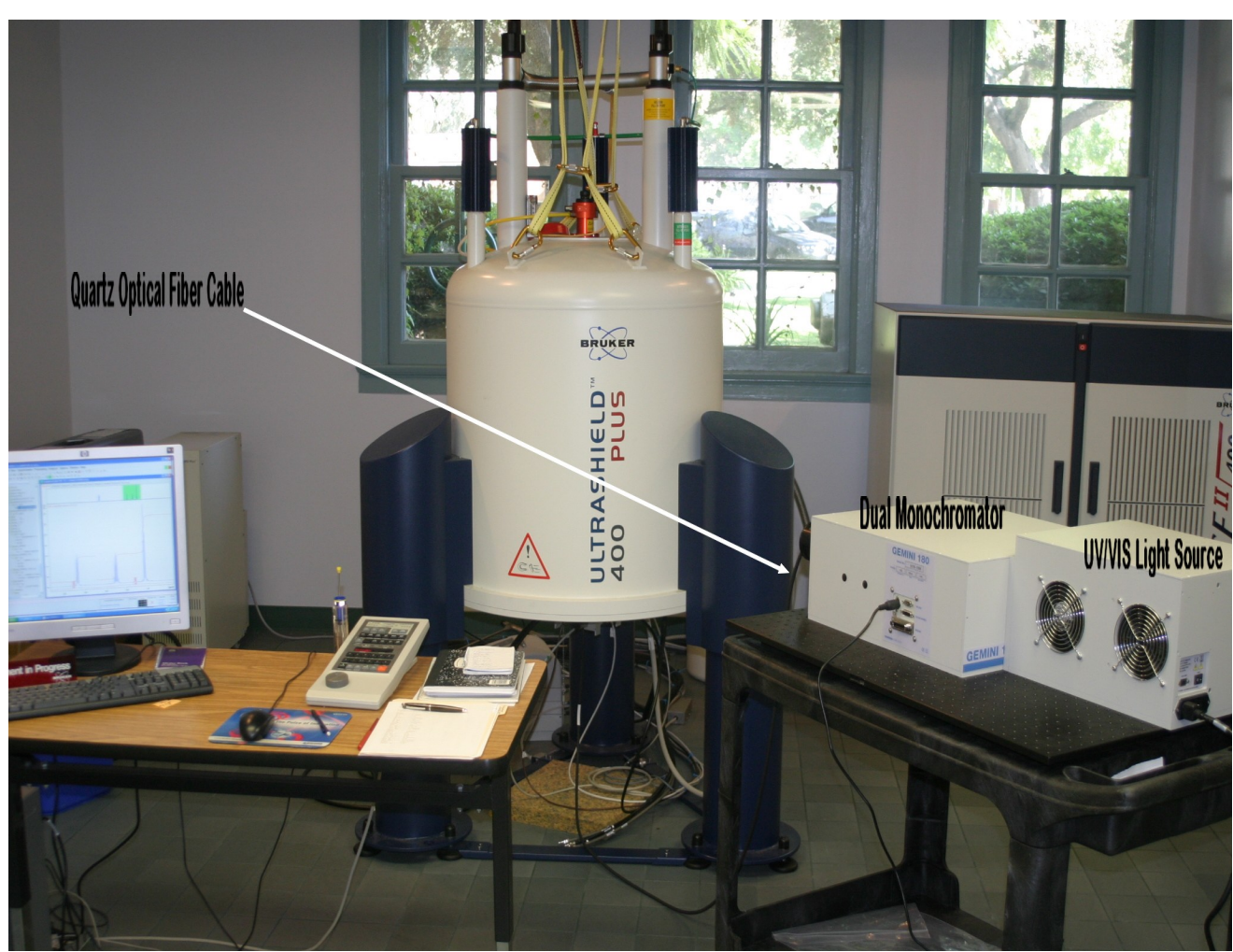

Figure 2. Apparatus setup for experiments.

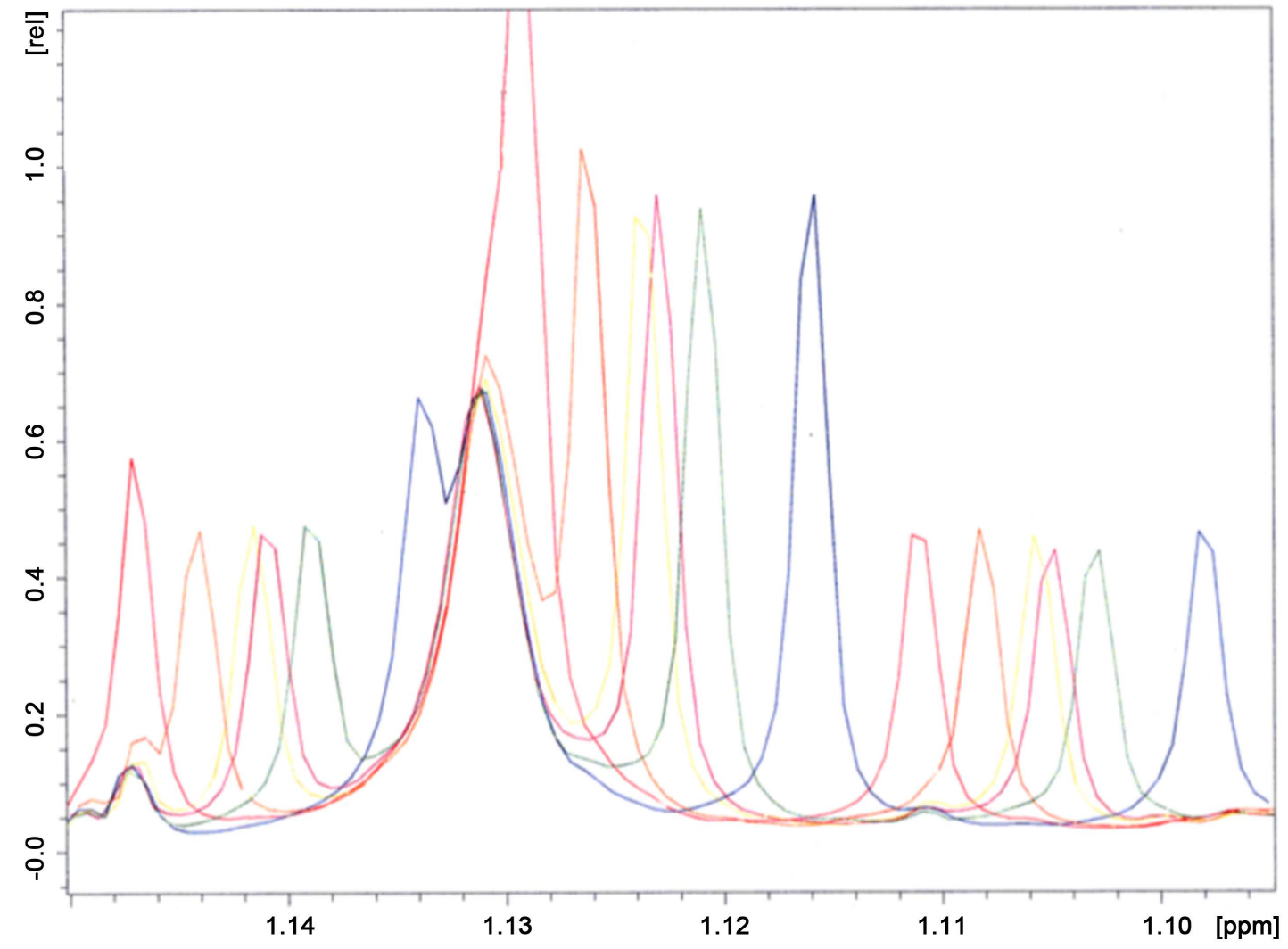

Figure 3. Early irradiation results indicating changes in the molecule at $1.10-1.15$ ppm for t-butyl group. 


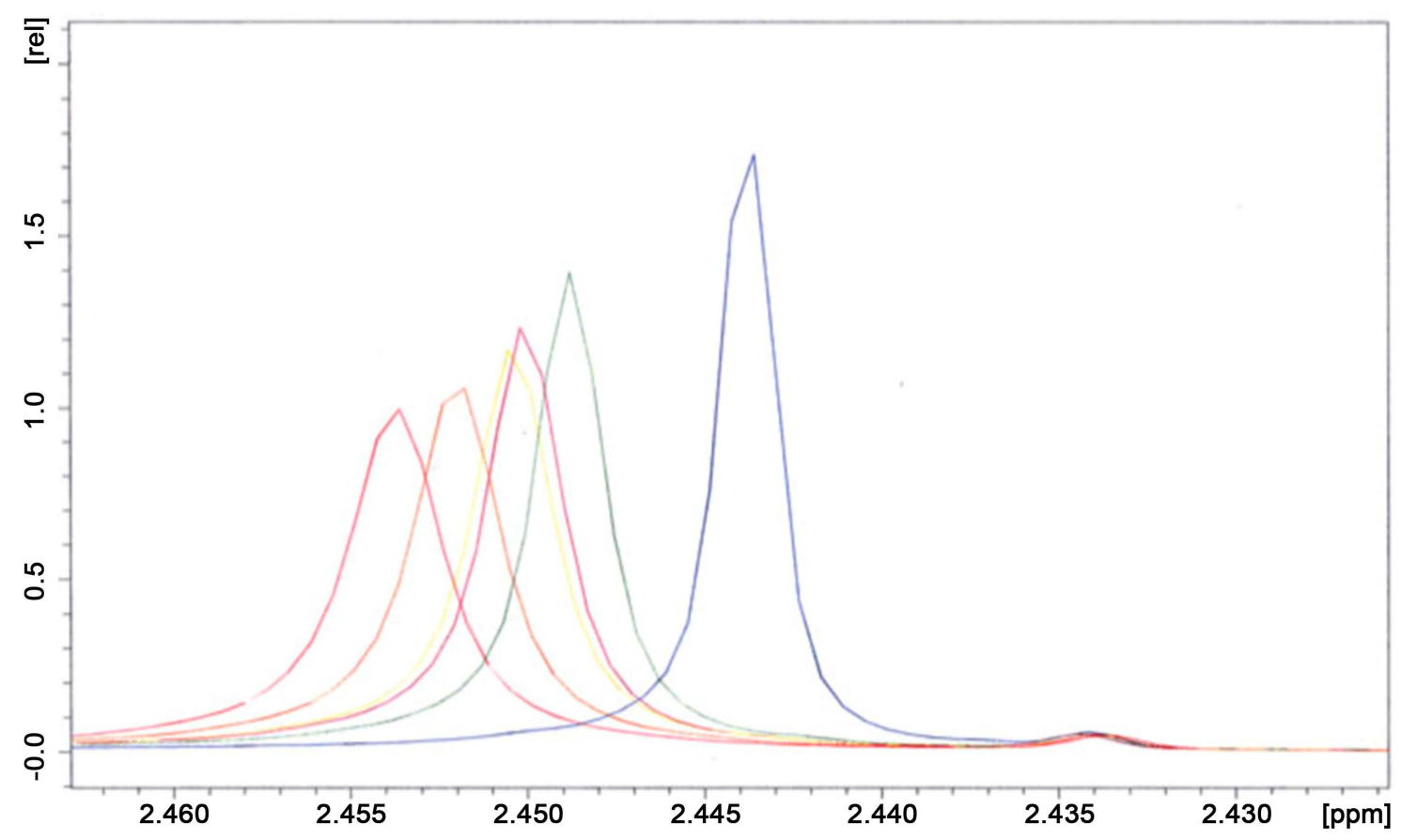

Figure 4. Early irradiation results indicating changes in the molecule at $2.43-2.46$ ppm.

Figure 5 shows the proton NMR of the aminoborane molecule at room temperature in $\mathrm{CDCl}_{3}$ before irradiation. This spectrum clearly shows two quartets. This clearly indicates the presence of two sites because of the rotation around the B-N bond. The ethyl group located on nitrogen experiences a different electronic environment by having the observed chemical shift. The t-butyl group located on boron has a chemical shift that causes it to shift closer to TMS, making it difficult to locate its exact position. However, it is somewhere in the 0 - 1.5 ppm range. The other triplet from the $\mathrm{CH}_{3}$ on the ethyl group on nitrogen is also located in this region; however its exact location is unknown. Impurities also exist in this region.

Figure 6 shows the effects of temperature on the aminoborane in $\mathrm{CD}_{2} \mathrm{Cl}_{2}$ as shown by Proton NMR. Temperatures shown are $20^{\circ} \mathrm{C},-10^{\circ} \mathrm{C},-40^{\circ} \mathrm{C}$ and $-70^{\circ} \mathrm{C}$. Usually in a compound we expect to see a dihedral angle of $0^{\circ}$, indicating a cis-orientation, and of $180^{\circ}$, indicating a trans-orientation. However, the appearance of multiple quartets as well as the different intensities suggests that the molecule is possibly at a $90^{\circ}$ angle or some other angle degrees. At low temperature the lifetime is longer and we are able to see the presence of the two other sites.

Figure 7 shows the effects of low temperature and irradiation in $\mathrm{CDCl}_{3}$ as shown by Proton NMR. The analysis of the NMR spectra at $-60^{\circ} \mathrm{C}$ with light is very interesting. At $-60^{\circ} \mathrm{C}$ and the presence of light $(\lambda=265 \mathrm{~nm})$ we observe a large change in the population of the two sites and this by itself indicates a modification in the rotation around boron-nitrogen bond in the excited state. We can compare this figure to the spectra in Figure 6, which shows aminoborane before irradiation at the following low temperatures: $-10^{\circ} \mathrm{C},-40^{\circ} \mathrm{C}$, and $-70^{\circ} \mathrm{C}$.

In the spectrum shown in Figure 8, we can see that by solvent effects the nonbonding electrons of DMSO migrates onto boron, and therefore boron cannot accept the electron from nitrogen. This prevents the observation of the two distinct alkyl groups on the nitrogen and allows for the presence of only one usual site. The irradiation this DMSO solution exhibits a complex unidentified NMR spectra.

\section{Conclusion}

As we observed in the NMR spectra $3-7$, aminoborane was the best candidate because the $\Delta \mathrm{G}^{* *}$ of activation for the rotation around the B-N bond was high enough to clearly see separate signals for each alkyl group on boron and nitrogen for the two sites at room temperature. For instance, the two quartets, seen in Figure 4, show that the different chemical shifts are related to the two different sites. We observed that if we go to even a lower temperature where the lifetime of the two sites will be appropriately longer, then we can read the differences of populations of the signals for the two sites by integration of NMR signals before and after irradiation of the mo- 


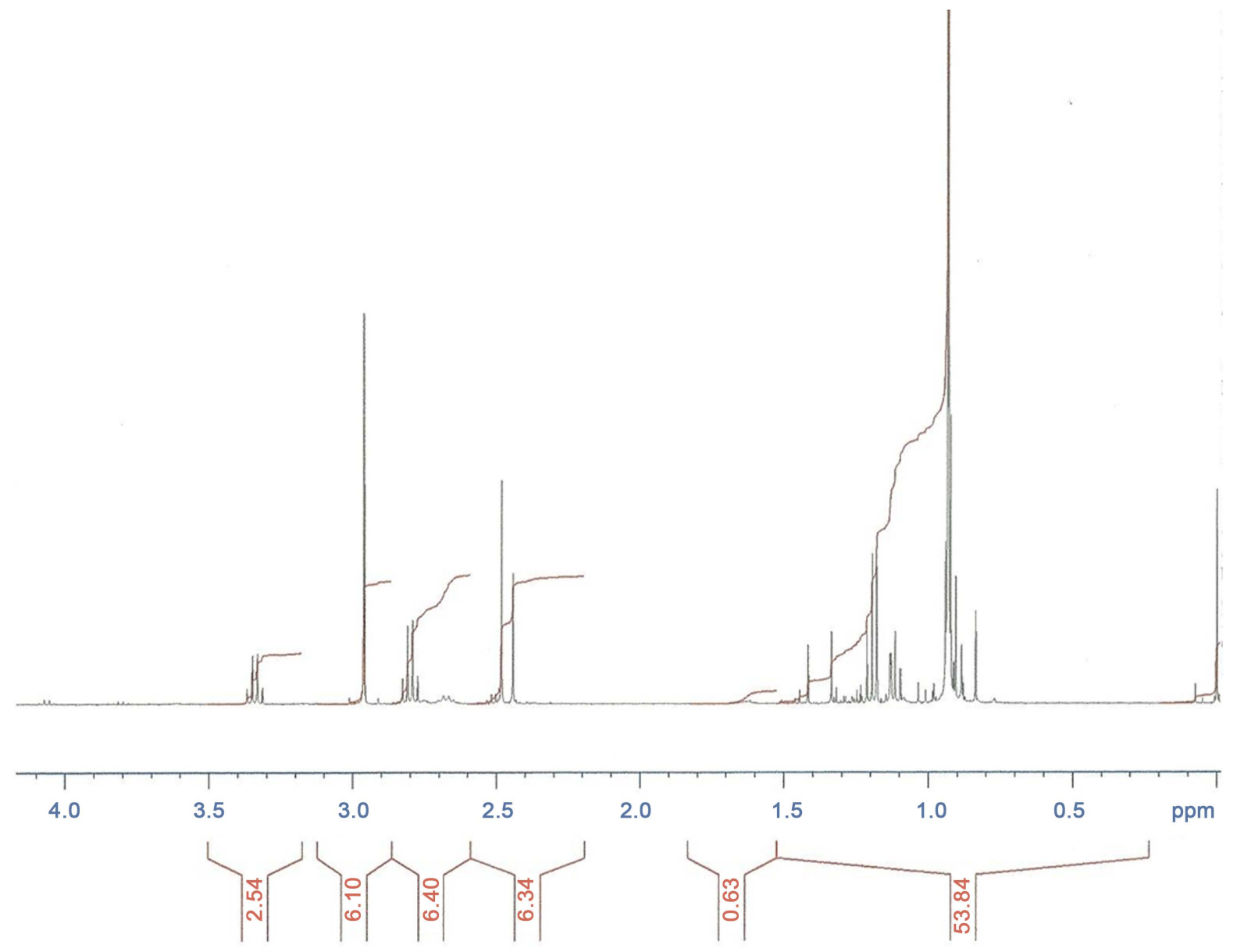

Figure 5. Proton NMR of aminoborane molecule at room temperature in $\mathrm{CDCl}_{3}$ before irradiation.

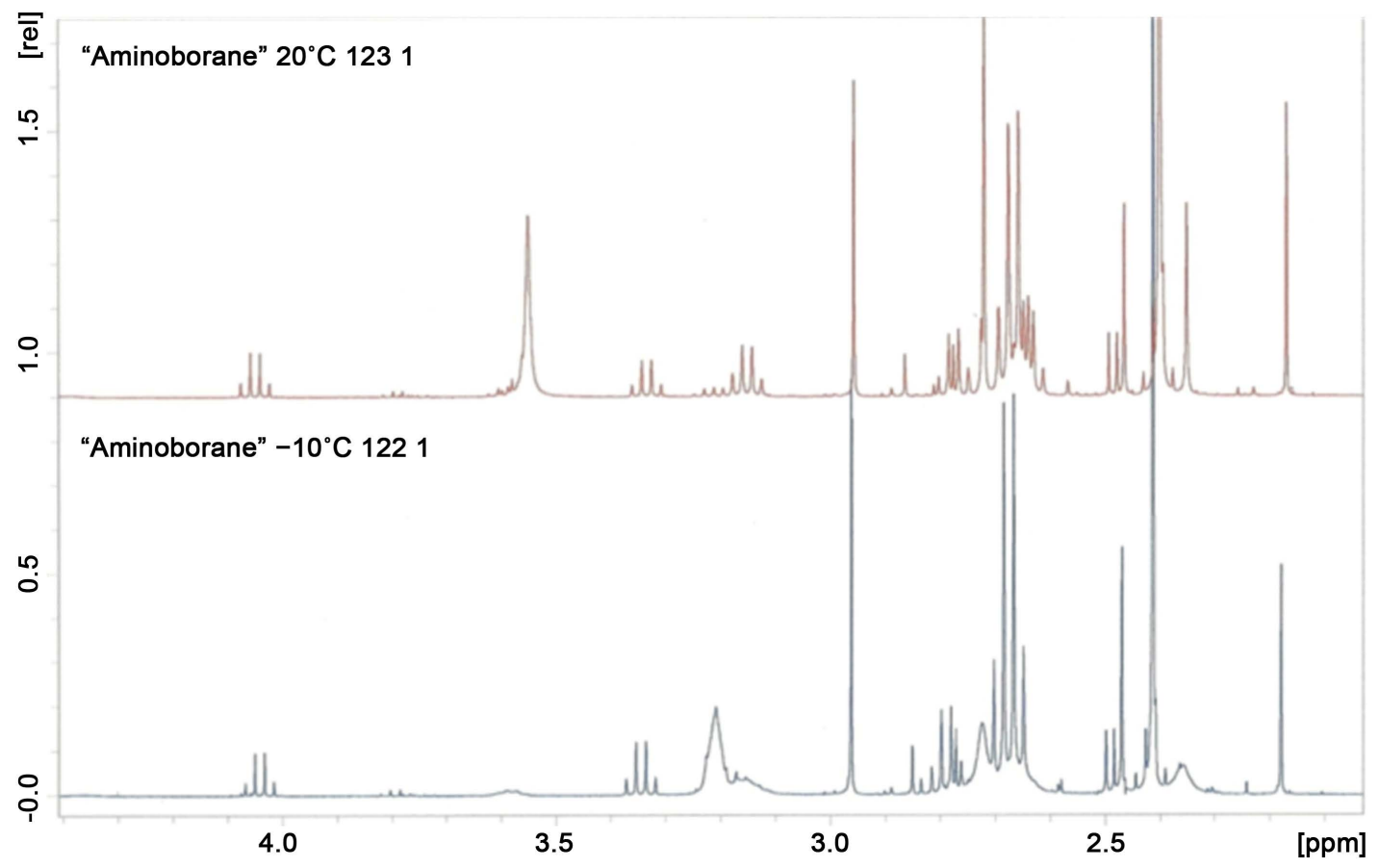




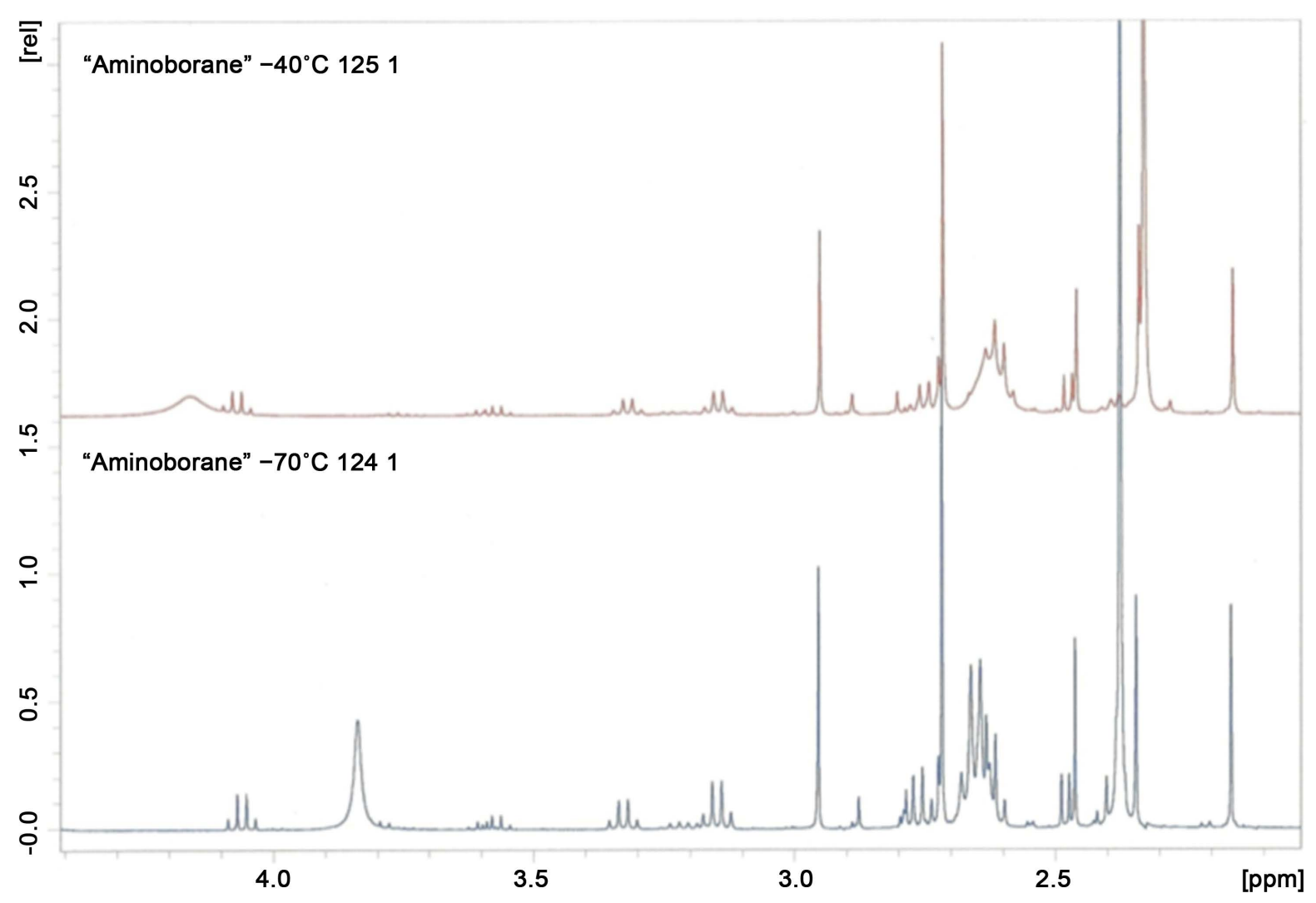

Figure 6. Effects of temperature on the aminoborane in $\mathrm{CD}_{2} \mathrm{Cl}_{2}$ as shown by proton $\mathrm{NMR}\left(20^{\circ} \mathrm{C},-10^{\circ} \mathrm{C},-40^{\circ} \mathrm{C},-70^{\circ} \mathrm{C}\right.$ respectively).

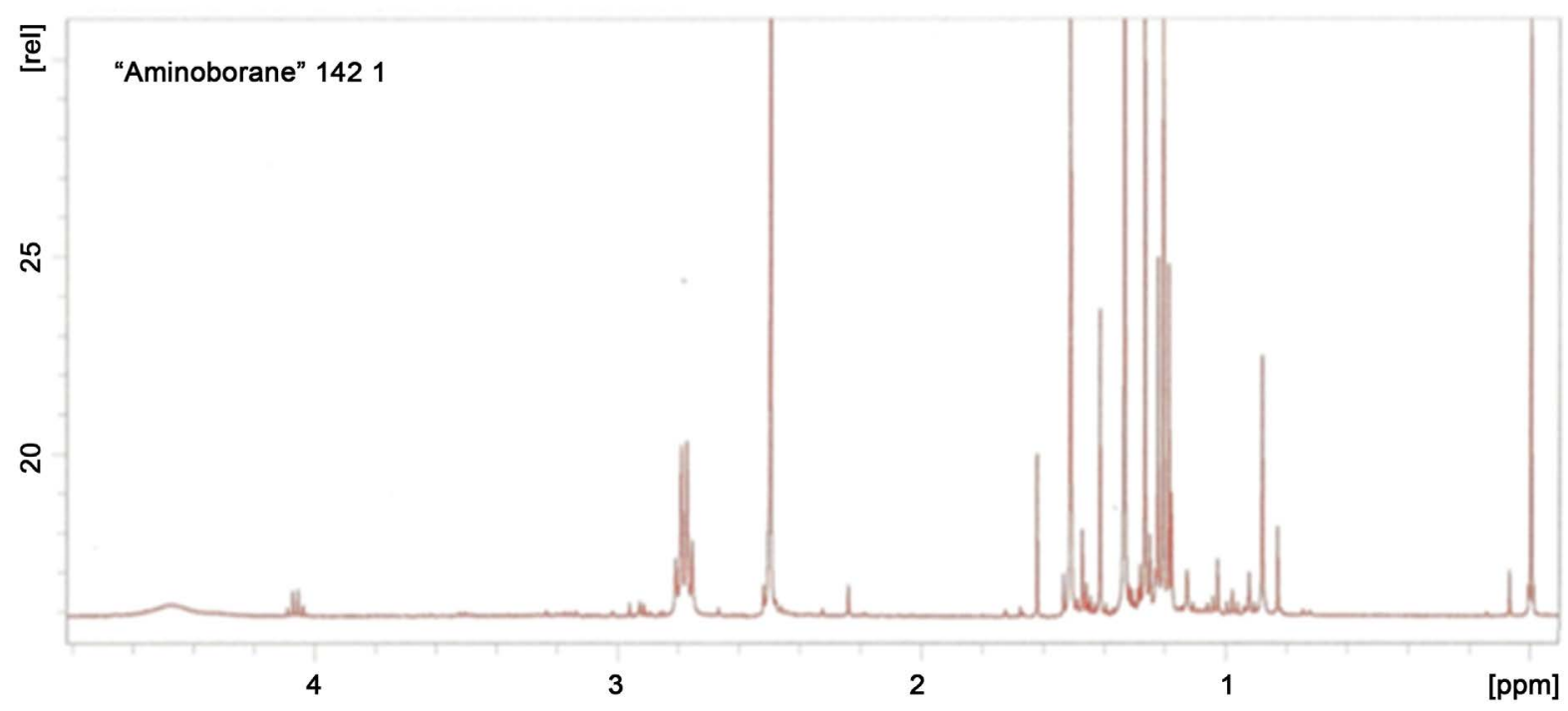

Figure 7. Effects of low temperature and irradiation in $\mathrm{CDCl}_{3}$ as shown by proton $\mathrm{NMR}$.

lecule inside the magnetic field. When the temperature was low, we saw a considerable difference between the population of the two sites before and after irradiation. This clearly showed that we would have had a rotation around the B-N bond in the excited state. As we experimentally observed electron transfer from nitrogen to boron and a twist around the B-N chemical bond, we can control the back electron transfer by using a model such as aminoborane, which helps the conversion of light to electricity or fuel. 


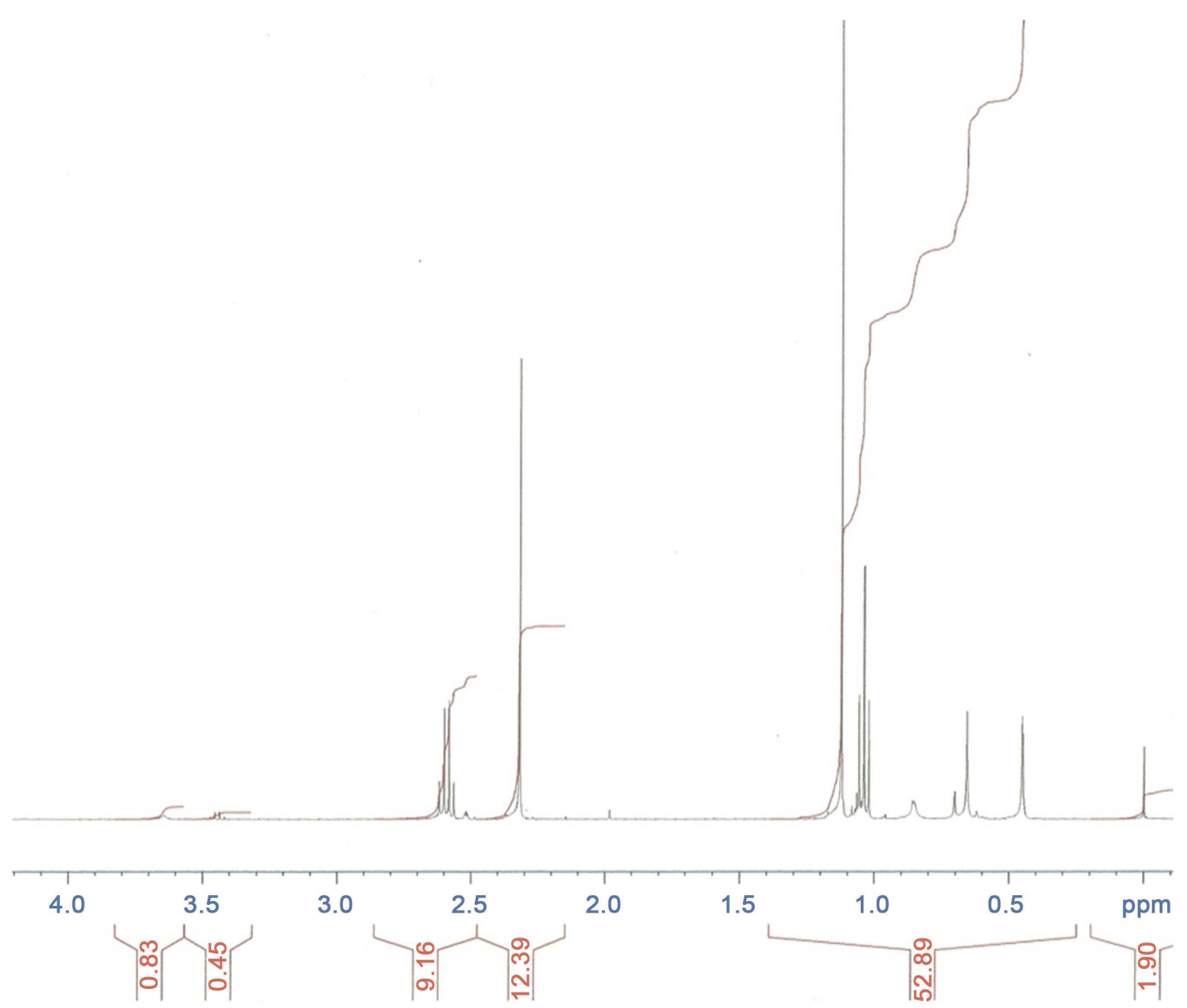

Figure 8. Proton NMR of aminoborane molecule at room temperature in DMSO before irradiation.

\section{Acknowledgements}

The authors are grateful to Frank Moralez for his technical expertise in the field of NMR and optics and Andrew Nguyen for helpful discussions during the performing the experiments. We are also grateful to the University of La Verne for financial support and W.M. Keck Foundation for generous establishment of the NMR Facility at the University of La Verne.

\section{References}

[1] Kosower, E., Dodiuk, H. and Kanety, H. (1978) Intramolecular Donor-Acceptor System. 4. Solvent Effects on Radiative and Nonradiative Processes for the Charge-Transfer States of N-Arylaminonaphthalenesulfonates. Journal of the American Chemical Society, 100, 4179-4188. http://dx.doi.org/10.1021/ja00481a028

[2] Rettig, W. (1981) External and Internal Parameters Affecting the Dual Fluorescence of p-Cyano-dialkylanilines. Journal of Luminescence, 26, 21-46. http://dx.doi.org/10.1016/0022-2313(81)90167-8

[3] Rettig, W. (1986) Charge Separation in Excited States of Decoupled Systems? TICT Compounds and Implications Regarding the Development of New Laser Dyes and the Primary Process of Vision and Photosynthesis. AngewandteChemie International Edition in English, 25, 971-988. http://dx.doi.org/10.1002/anie.198609711

[4] Rullière, C., Grabowski, Z. and Dobkowski, J. (1987) Picosecond Absorption Spectra of Carbonyl Derivatives of Dimethylaniline: The Nature of the Tict Excited States. Chemical Physics Letters, 137, 408-413. http://dx.doi.org/10.1016/0009-2614(87)80224-5

[5] Hornyak, D., Nguyen, A. and Parchamazad, I. (2010) Investigation of Back-Electron-Transfer Control in Aminoborane Derivatives Using Dynamic NMR. 239 ${ }^{\text {th }}$ ACS National Meeting, Division of Fuel Science and Technology, San Francisco. 
[6] Barfield, P., Lappert, M. and Lee, J. (1968) Nuclear Magnetic Resonance Studies of л-Bonding in Aminoboranes. Part I. Ambient Temperature Spectra. Journal of the Chemical Society A: Inorganic, Physical, Theoretical, 554-554.

[7] Brown, C., Cragg, R., Miller, T. and Smith, D. (1988) Restricted Rotation about the B-N Bond in Aminoboranes: The Determination of Activation Parameters Using 13C NMR. Journal of Organometallic Chemistry, 342, C17-C18.

[8] Majumdar, D., Sen, R., Bhattacharyya, K. and Bhattacharyya, S. (1991) Twisted Intramolecular Charge Transfer of p-(N,N-Dimethylamino)benzonitrile: An Approximate Quantum Mechanical Study Including Solvation Effects. Journal of Physical Chemistry, 95, 4324-4329. http://dx.doi.org/10.1016/0009-2614(87)80224-5

[9] Visser, R. and Varma, C. (1980) Source of Anomalous Fluorescence from Solutions of 4-N,N-Dimethylaminobenzonitrile in Polar Solvents. Journal of the Chemical Society, Faraday Transactions, 2, 453-453. http://dx.doi.org/10.1039/f29807600453

[10] Rotkiewicz, K., Grellmann, K. and Grabowski, Z. (1973) Reinterpretation of the Anomalousfluorescense of p-N,NDimethylamino-benzonitrile. Chemical Physics Letters, 19, 315-318. http://dx.doi.org/10.1016/0009-2614(73)80367-7

[11] Gordon, M. (1975) The Exciplex. Academic Press, New York.

[12] Parchamazad, I. (2011) Investigation of Charge Transfer Exited States in Organic Molecules Using Dynamic NMR. Presented at Southern California Users of Magnets (SCUM) Meeting, University of La Verne, La Verne.

[13] Niedenzu, K. and Dawson, J. (1959) Boron-Nitrogen. II. Aminoboranes, Part 1: The Preparation of Organic Substituted Aminoboranes through a Grignard Reaction. Journal of the American Chemical Society, 81, 5553-5555. http://dx.doi.org/10.1021/ja01530a010

[14] Perry, M. (1998) Synthesis of Aminoborane Derivatives. Senior Thesis, University of La Verne, La Verne.

[15] Pfeiffr, R. (1995) Photoisomerization about the N-B Bond: TICT State Formation and Synthesis of an Aminoborane. Senior Thesis, University of La Verne, La Verne.

[16] Weimer, M. (1994) Preparation of $n$-Butylboron Dichloride for the Synthesis of N-N'-Ethylmethyl-t-Butyl-n-ButylBoroamine for the Study of the Boron-Nitrogen Bond. Senior Thesis, University of La Verne, La Verne.

[17] Hornyak, D. (2010) Back Electron Transfer Control in Aminoborane Derivatives. Senior Thesis, University of La Verne, La Verne.

\section{Abbreviations}

TICT: Twisted Intramolecular Charge Transfer 